\title{
Effect of milnacipran on suicidality in patients with mild to moderate depressive disorder
}

\author{
This article was published in the following Dove Press journal: \\ Neuropsychiatric Disease and Treatment \\ 30 July 2009 \\ Number of times this article has been viewed
}

\section{Alla Avedisova \\ Vladimir Borodin \\ Ksenia Zakharova \\ Artem Aldushin}

Department of Borderline Psychiatry, FGU State Scientific Research Center of Social and Forensic Psychiatry

"V.P. Serbsky", Moscow, Russia
Correspondence: Alla Avedisova 47 Volokolamskoe shosse, Moscow, Russia

Tel +7 4951903627

Fax +7 8499904009

Email aavedisova@hotmail.com

\begin{abstract}
The presence of suicidal manifestations (thoughts and behavior) was studied in a cohort of 30 patients with mild to moderate depression during a 6-week treatment with the serotonin-norepinephrine reuptake inhibitor, milnacipran. At baseline mild suicidal thoughts were present in $46.7 \%$ of patients, the mean Hamilton Depression Rating Score $\left(\mathrm{HDRS}_{17}\right.$ ) was $23.9 \pm 1.8$ and the mean suicidality score on the Beck Scale for Suicidal Ideation (BSS) was $4.9 \pm 4.9$. Suicidal thoughts decreased progressively throughout the study in parallel with other depressive symptoms. At no time during treatment was there any indication of an increased suicidal risk. Notably, the items retardation and psychic anxiety on the $\mathrm{HDRS}_{17}$ decreased in parallel. This may possibly explain the lack of any "activation syndrome", which is occasionally observed at the early stages of therapy with some antidepressants and may be linked to a temporary increase in suicidal ideation. To our knowledge this is the first detailed report of suicidality during treatment with milnacipran.
\end{abstract}

Keywords: suicidality, milnacipran, depression

\section{Introduction}

There is a clear association between suicide and depression. Mood disorders, principally major depressive disorder and bipolar disorder, are associated with about $60 \%$ of all suicides. ${ }^{1-6}$ An often-quoted figure is that about $15 \%$ of patients with major depression will eventually die by suicide. ${ }^{7,8}$ This estimation is, however, derived largely from studies of severely depressed inpatients. More recently a more conservative lifetime suicide risk in the general population of depressed patients of about $6 \%$ has been calculated. ${ }^{9}$ This discrepancy has been erroneously interpreted by many primary care physicians and certain psychiatrists as evidence that overt suicidal behavior occurs only in severe depression. This notion can lead to inappropriate management of less severely depressed patients.

The more recent clinical literature clearly supports the idea that suicidality (thoughts and behavior) is associated with any type of depressive disorder and any degree of severity. ${ }^{10,11}$ Antidepressant therapy, which is effective in managing the symptoms of major depressive disorder, is expected to reduce or prevent suicidal behavior associated with depression. ${ }^{12,13}$ This hypothesis has been questioned, however, by large multi-study analyses that have suggested that, at least in certain patients groups, antidepressants may enhance or even induce suicidal ideation. ${ }^{14,15}$ In 2004 the US Food and Drug Administration warned of the possible enhancement of suicidal ideation in pediatric and adult patients receiving modern antidepressants especially at the beginning of therapy

submit your manuscript | www.dovepress.con 
and at dose increase. This interpretation is controversial and the results of other meta-analyses ${ }^{16,17}$ have not supported the enhancement of suicidal ideation in adult patients with shortterm antidepressant treatment compared to placebo. The latest analyses indicated that patients receiving SSRIs and tricyclic antidepressants (TCAs) do not show significantly more suicidality than patients receiving placebo. ${ }^{6,18}$ Indeed several studies have shown that suicide rates have decreased since the introduction of modern antidepressants supporting the hypothesis that the use of antidepressants may prevent suicide. ${ }^{19,20}$

In the light of this controversy, the effect of an antidepressant, especially a recently introduced one, on suicidal ideation clearly remains an important question. Thus, in addition to assessing the general efficacy and tolerability of milnacipran $\left(\mathrm{Ixel}^{\circledR}\right)$, a serotonin and norepinephrine reuptake inhibitor (SNRI) ${ }^{21}$ recently introduced into Russia, the primary aim of the present investigation was to observe the effects of the drug on the occurrence and intensity of suicidal thoughts and behavior in patients with mild to moderate depressive disorders and to assess whether suicidality decreased in parallel with other depressive symptoms.

\section{Methods}

The investigation was a 6-week open label study in patients enrolled from an outpatient clinic (Psychiatric Hospital N12) in Moscow. Inclusion criteria were: age 16 to 65 years, a diagnosis of mild to moderate depression which could be either a single depressive episode, recurrent depressive disorder, bipolar disorder, dysthymia, cyclothymia, continuous depressive reaction within an adaptation disorder or other mood disorder. Exclusion criteria included severe depression with psychotic manifestations; schizophrenia and schizoaffective disorder; abuse of alcohol and other psychoactive agents; pronounced manifestations of psychoorganic syndrome (or chronic brain disorder), including paroxysmal disorders; severe or decompensated somatic pathology requiring continuous polypharmacotherapy; pregnancy and lactation; participation in clinical trials within 30 days prior to start-up of the present study; and contradictions to milnacipran treatment. All diagnoses were based on ICD-10 criteria.

The study was approved by the local ethics committee and was carried out in accordance with the Declaration of Helsinki. All patients gave their written informed consent.

In addition to a standard psychiatric and general clinical examination (including urinalysis, hematology and biochemistry, electrocardiogram), the 17-item Hamilton Depression Rating Scale $\left(\mathrm{HDRS}_{17}\right)$, Clinical Global Impression (CGI), Beck Depression Inventory (BDI), Beck Scale for Suicidal Ideation (BSS) ${ }^{22}$ and the Udvalg for Kliniske Undersøgelser Side Effect Rating scale (UKU-side-effects) were used.

Milnacipran was administered initially, for 2 to 3 days, at 25 to $50 \mathrm{mg}$ /day depending on the severity of depressive symptoms. If the drug was well tolerated the dose was increased to $100 \mathrm{mg} /$ day (50 $\mathrm{mg}$ twice daily).

The statistical significance of changes from baseline during the study were determined using paired Student's t-test and Wilcoxon nonparametric test using the statistical and analytical software package STATISTICA. The significance level was set as $P<0.05$

\section{Results}

Thirty patients were enrolled in the study. Demographic characteristics of the patients are shown in Table 1. Women

Table I Patients' clinical demographics

\begin{tabular}{|c|c|c|c|}
\hline \multirow{2}{*}{\multicolumn{2}{|c|}{ Female/Male }} & $\mathbf{N}$ & $\%$ \\
\hline & & $26 / 4$ & $86.7 / 13.3$ \\
\hline \multicolumn{2}{|l|}{ Mean age (yr) } & \multicolumn{2}{|c|}{$41.4 \pm 9.6$} \\
\hline \multirow[t]{3}{*}{ Highest education level } & Higher & 18 & 60 \\
\hline & Secondary & 10 & 33.3 \\
\hline & Primary & 2 & 6.7 \\
\hline \multirow[t]{2}{*}{ Professional activity } & Employed & 18 & 60 \\
\hline & Unemployed & 12 & 40 \\
\hline \multirow[t]{2}{*}{ Marital status } & Married & 12 & 40 \\
\hline & Unmarried & 18 & 60 \\
\hline \multirow[t]{2}{*}{ Diagnosis (ICD-I0) } & $\begin{array}{l}\text { Single major } \\
\text { depressive episode }\end{array}$ & 18 & 60 \\
\hline & $\begin{array}{l}\text { Recurrent major } \\
\text { depressive disorder }\end{array}$ & 12 & 40 \\
\hline \multirow[t]{5}{*}{ Type of depression } & Apathetic & 10 & 33.3 \\
\hline & Anxious & 6 & 20 \\
\hline & Asthenic & 6 & 20 \\
\hline & Hysteric & 6 & 20 \\
\hline & Hypochondriac & 2 & 6.7 \\
\hline \multicolumn{4}{|c|}{ Severity of current episode } \\
\hline \multirow[t]{2}{*}{ Total } & Mild & 4 & 13.3 \\
\hline & Moderate & 26 & 86.7 \\
\hline \multirow[t]{2}{*}{ Single episode } & Mild & 2 & \\
\hline & Moderate & 16 & \\
\hline \multirow[t]{2}{*}{ Recurrent episode } & Mild & 2 & \\
\hline & Moderate & 10 & \\
\hline
\end{tabular}


comprised $86.6 \%$ of the cohort and the mean age of patients was $41.4 \pm 9.5$ (all values are given as mean \pm standard deviation). In general the educational level was high with $60 \%$ of patients having a higher (university) education and 33.3\% a secondary education. Only $40 \%$ of patients were married.

The majority of patients $(60 \%)$ had a diagnosis of a single depressive episode. Most patients (86.6\%) at baseline were considered to be moderately depressed. The baseline HDRS was $23.9 \pm 1.8$ and BDI was $37.7 \pm 3.9$. The apathetic form of depression was the most frequent while anxious, asthenic and hysteric forms were also common. The hypochondriac form was only found in 2 patients.

Two patients withdrew from the study, one at the end of the first week of treatment because of adverse events (nausea) and the other at the end of the 4th week of treatment due to lack of efficacy of the treatment.

\section{Antidepressant efficacy}

The efficacy of the antidepressant treatment was demonstrated by the steady reduction of the mean HDRS $_{17}$ score throughout the study (Figure 1). Statistically significant differences compared to baseline occurred from the first week of therapy. At endpoint (after 6 weeks treatment) mean HDRS $_{17}$ was $9.5 \pm 4.4$ and $60 \%$ of patients were treatment responders (reduction of baseline $\mathrm{HDRS}_{17}$ of at least $50 \%$ ). BDI scores showed a similar progressive reduction with a significant difference $(P<0.05)$ from baseline occurring from the third week of treatment. The mean BDI score at endpoint was $21.4 \pm 6.1$ (data not shown).

The mean baseline score on the CGI (Severity) scale was $3.9 \pm 0.4$ indicating a moderate severity. This value decreased progressively with a significant difference $(P<0.05)$ from baseline occurring after 3 weeks of treatment. At endpoint the mean CGI (Severity) score was $2.1 \pm 0.3$, indicating borderline depression (data not shown).

\section{Suicidality}

At baseline mild suicidal ideation was found in 14 patients (46.7\%). No current or previous suicidal attempts, planning or preparation were noted in any patient.

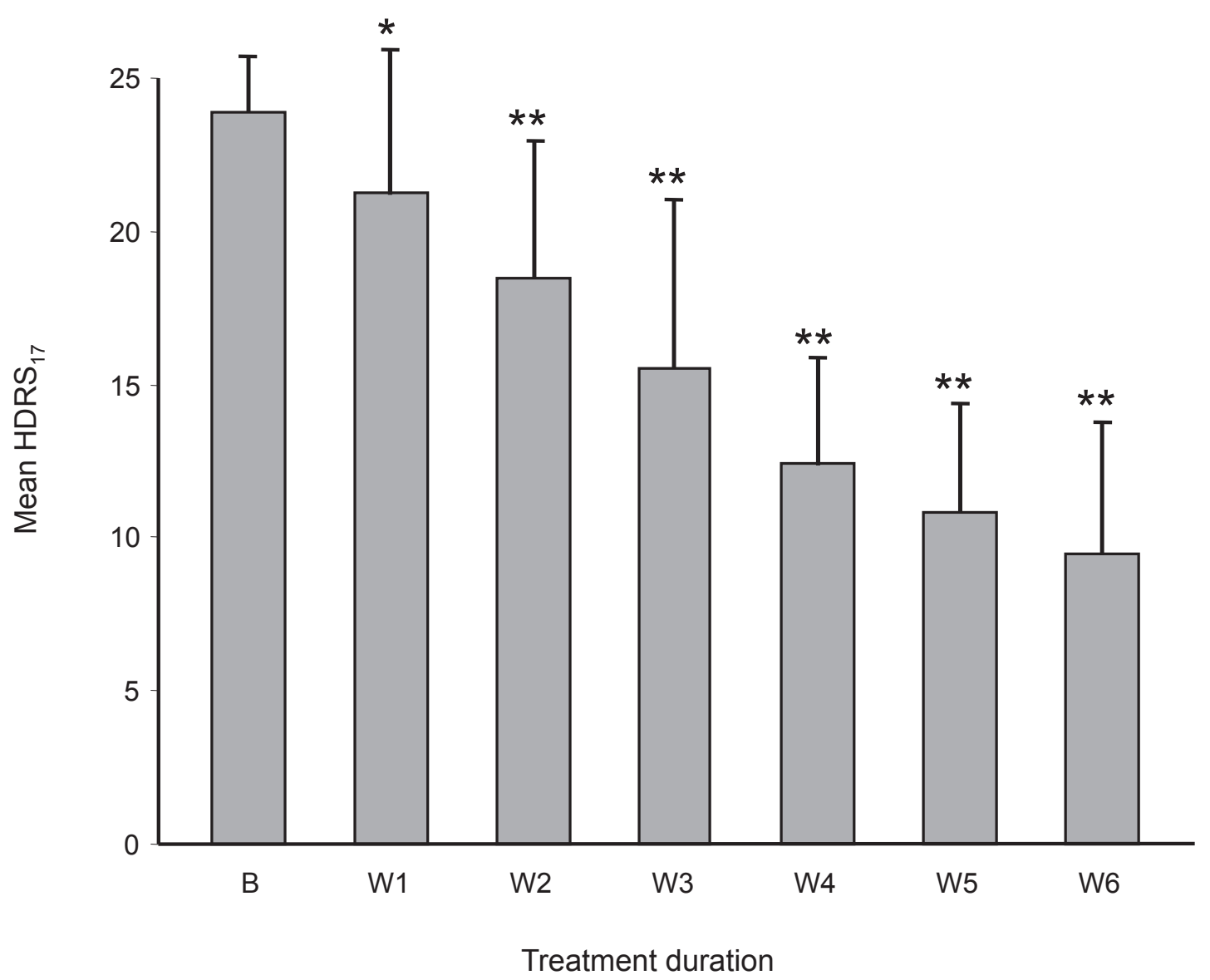

Figure I Reduction of mean global $\mathrm{HDRS}_{17}$ scores during the study.

Notes: ${ }^{*} P<0.05$; ${ }^{*} P<0.01$ compared to baseline values.

Abbreviations: B, baseline; WI to W6, number of weeks of treatment. 
A total of 57 suicidal manifestations were found during the study (Table 2). The most common suicidal manifestations were thoughts of "inanity of existence", thoughts that death could resolve existing sufferings, suicidal thoughts and unwillingness to live.

More rarely, different signs of suicidality were reported: visualization of own suicide, death or funeral, as well as (supraliminal) death instinct. Only in a few patients did these suicidal ideations develop into either ideational compulsions (compulsive thoughts and concepts of death and funerals) or suicidal fantasies. Suicidal compulsive thoughts and concepts developed in patients with asthenic and hypochondriac depression, and suicidal fantasies in patients with hysteric depression. No other relationships, including those between suicidal phenomena and patients personality characteristics were detected.

The entry criteria of this study allowed the recruitment of patients with a single depressive episode, recurrent depressive disorder, chronic depression, bipolar disorder, dysthymia or cyclothymia. Unfortunately subanalysis of the different types of depression was not possible due to the small numbers of each subtype.

Mean baseline BSS score was $4.9 \pm 4.9$, indicating a mild level of suicidality in this group of patients. Suicidality decreased rapidly with a significant reduction observed from the second week of treatment (Table 3). After 4 weeks of treatment, mean BSS scores were close to zero indicating an absence of any suicidal activity in treated patients.

Table 2 Suicidality (thoughts and behavior) reported during the study

\begin{tabular}{lll}
\hline & $\begin{array}{l}\text { Number } \\
\text { of patients } \\
\text { reporting }\end{array}$ & $\begin{array}{l}\text { \% of all suicidal } \\
\text { thoughts and } \\
\text { behavior }\end{array}$ \\
\hline Inanity of existence thoughts & II & 19.4 \\
Thoughts of death & 9 & 15.8 \\
Suicidal thoughts & 7 & 12.3 \\
Unwillingness to live & 6 & 10.5 \\
Visualizations of suicide & 5 & 8.8 \\
Visualizations of death & 4 & 7 \\
Visualizations of funerals & 4 & 7 \\
Death instinct & 4 & 7 \\
Suicidal compulsive thoughts & 2 & 3.5 \\
Funerals compulsive thoughts & 2 & 3.5 \\
Suicidal fantasies & 2 & 3.5 \\
Death compulsive thoughts & I & 1.7 \\
Total occurrences of suicidal & 57 & 100 \\
thoughts or behavior & & \\
\hline
\end{tabular}

aSome patients reported more than one suicidal manifestation.
None of the patients showed any increase in BSS score during milnacipran treatment indicating an absence of any "activation syndrome", sometimes observed at the early stages of therapy with certain antidepressants. ${ }^{10}$

Analysis of the "suicidal thoughts/attempts" item of the $\mathrm{HDRS}_{17}$ at baseline showed a score of 1 in 10 patients $(33.3 \%)$ and of 2 in one patient. The number of patients with scores 1 or 2 decreased progressively throughout the study. At endpoint only 3 patients had a score of 1 , all others scoring zero.

The HDRS 17 items of "psychic anxiety" and "retardation" showed a similar progressive reduction throughout the study. The rate of decrease of the two items was approximately parallel (Figure 2). At the end of the study anxiety was reduced by $82 \%$ and retardation by $88 \%$. The anxiety/retardation ratio remained essentially constant during milnacipran therapy confirming the absence of any "activation syndrome". ${ }^{10}$

\section{Adverse events}

Adverse events (AEs) with milnacipran therapy were scored with the UKU Side Effect Rating in all patients. A total of 48 AEs were recorded during the study (Table 4). No AE was scored with a severity rating greater than 2 , indicating that they did not significantly affect the patients' daily life. The most frequent AEs, which occurred in more than 5 patients, were nausea, anxiety, tachycardia and dizziness. The majority of AEs occurred within the first week of treatment with milnacipran and tended to resolve spontaneously from the beginning of the second week. Seventy percent of all AEs had resolved by the third week of treatment.

\section{Discussion}

The cohort of the present study was a relatively classical mild to moderately depressed population although the proportion of women (86\%) was somewhat higher

Table 3 Evolution of mean global Beck Scale for Suicidal Ideation scores during the study

\begin{tabular}{lll}
\hline & Mean (SD) & $P^{\mathbf{a}}$ \\
\hline Baseline & $4.87(4.91)$ & \\
Week I & $4.52(4.38)$ & NS \\
Week 2 & $2.00(2.83)$ & 0.008 \\
Week 3 & $1.10(2.10)$ & 0.0007 \\
Week 4 & $0.20(0.33)$ & 0.0001 \\
Week 5 & $0.10(0.33)$ & $>0.0001$ \\
Week 6 & $0.10(0.33)$ & $>0.0001$ \\
\hline
\end{tabular}

${ }^{a}$ Significance compared to baseline values. 


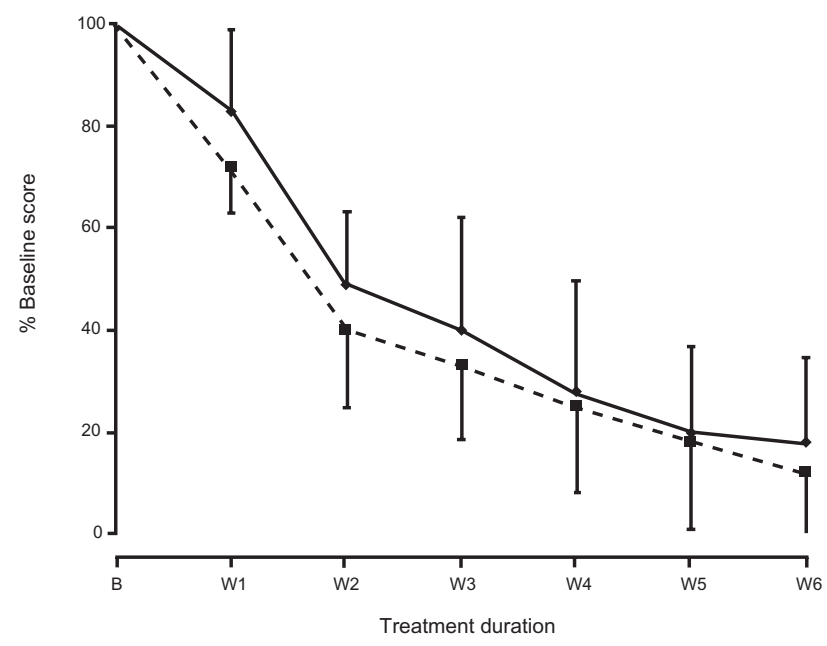

Figure 2 Reduction of mean "anxiety" and "retardation" scores during the study. Notes: "Anxiety" was the score of item 10 of the HDRS ${ }_{17}$ "Retardation" was the score of item 8 of the HDRS

Abbreviations: $\mathrm{B}$, baseline; $\mathrm{WI}$ to $\mathrm{W} 6$, number of weeks of treatment; Solid line, "anxiety" item; broken line, "retardation" item.

than that commonly reported. At baseline nearly $50 \%$ of patients reported some form of suicidal ideation although none reported previous suicidal attempts, planning or preparation. Almost all of the suicidal manifestations observed during the study were limited to the cognitive sphere (thoughts, concepts). In addition, in the majority of cases, suicidal manifestations occurred only occasionally, and the suicidal fantasies, reported in only 2 patients, were transient (up to 1 to 2 hours per day over several days).

The wide prevalence of different suicidal manifestations in patients with mild to moderate depressive disorders shown here is important since, even in absence of a behavioral component they are considered to be a potent predictor of future suicidal behavior. ${ }^{2,13,23}$
Regular patient assessment with $\mathrm{HDRS}_{17}$, CGI and BDI showed a progressive regression of depressive symptoms throughout the study. There were few AEs, all of them mild as assessed by the UKU Side Effect Rating. Only one patient withdrew because of side effects.

The progressive regression of suicidal thoughts during milnacipran therapy observed at weekly testing showed no enhancement of suicidal risk at early stages of antidepressant pharmacotherapy. On the contrary, the administration of milnacipran led to a progressive and almost total reduction of all suicidal manifestations. The drug's effects on important aspects of the clinical profile of depression such as anxiety and retardation appeared to be well balanced. This may have contributed to the lack of "activation syndrome" which has been associated increased suicide risk. ${ }^{10}$ Even the occurrence of AEs such as anxiety during milnacipran therapy did not negatively affect the general suicidality of patients.

This study suffers from several weaknesses, namely the small cohort studied, its open nature and the relatively short observation period ( 6 weeks). To our knowledge this is the first study to have analyzed suicidality and depressive symptoms in parallel during the treatment with milnacipran. A meta-analysis of suicidal behaviors and ideation in clinical trials in depression with another SNRI, duloxetine, has also demonstrated the absence of increased risk of suicidal behaviors or ideation during treatment with the SNRI compared with placebo. ${ }^{24}$

From this small open study there is a clear suggestion that mild suicidal thoughts can be relatively common even in mild to moderately depressed patients. During treatment with milnacipran suicidal thoughts regressed progressively in parallel with other depressive symptoms. At no time was there any noticeable increase in suicidal thoughts even in patients who reported anxiety as an

Table 4 Adverse events

\begin{tabular}{|c|c|c|c|c|c|c|}
\hline & \multicolumn{6}{|c|}{ Number of adverse events recorded } \\
\hline & Week I & Week 2 & Week 3 & Week 4 & Week 5 & Week 6 \\
\hline Number of patients & 29 & 29 & 29 & 28 & 28 & 28 \\
\hline Nausea & 15 & 10 & 2 & 0 & 0 & 0 \\
\hline Anxiety & 10 & 7 & 5 & 2 & 2 & 2 \\
\hline Tachycardia & 8 & 5 & I & 0 & 0 & 0 \\
\hline Dizziness & 7 & 3 & 0 & 0 & 0 & 0 \\
\hline Sweating & 5 & 5 & 5 & 4 & 2 & 1 \\
\hline Somnolence & 2 & 2 & 0 & 0 & 0 & 0 \\
\hline Abnormal ejaculation & I & I & I & 1 & 0 & 0 \\
\hline Total number of adverse events & 48 & 33 & 14 & 7 & 4 & 3 \\
\hline
\end{tabular}


adverse event. This study clearly warrants replication in a larger cohort which should be followed for a longer period of time.

\section{Acknowledgments and disclosures}

We thank Dr Mike Briley for his help in correcting the manuscript. After completion of the study and its analysis, Pierre Fabre Médicament, manufacturers of milnacipran, offered to support the publication of the study with an unconditional educational grant. They played no role in the interpretation of the data or in writing the manuscript.

\section{References}

1. Isometsa ET, Henriksson MM, Aro HM, et al. Suicide in major depression. Am J Psychiatry. 1994;151:530-536.

2. Bradvik L, Berglund M. Suidical ideation in severe depression. Eur Arch Psychiatry Clin Neurosci. 2000;250:139-143.

3. Bradvik L, Berglund M. Suicide in severe depression related to treatment: depressive characteristics and rate of antidepressant overdose. Eur Arch Psychiatry Clin Neurosci. 2004;255:245-250.

4. Bradvik L. The occurrence of suicide in severe depression related to the months of the year and the days of the week. Eur Arch Psychiatry Clin Neurosci. 2002;252:28-32.

5. Gibbons RD, Hur K, Bhaumik DK, et al. The relationship between antidepressant medication use and rate of suicide. Arch Gen Psychiatry. $2005 ; 62: 165-172$.

6. Martinez C, Rietbrock S, Wise L, et al. Antidepressant treatment and the risk of fatal and non-fatal self harm in first episode depression: nested case-control study. BMJ. 2005;330:389-396.

7. Guze SB, Robins E. Suicide and primary affective disorders. $B r J$ Psychiatry. 1970;117:437-438.

8. Goodwin FK, Jamison KR. Manic-Depressive Illness: Bispolar Disorders and Recurrent Depression, 2nd Edition Oxford University Press, USA. 2007:65-72.

9. Inskip HM, Harris EC, Barracough B. Lifetime risk of suicide for affective disorder, alcoholism, and schizophrenia. Br J Psychiatr. 1998;172:35-37.
10. Culpepper L, Davidson JRT, Dietrich AJ, et al. Suicidality as a possible side effect of antidepressant treatment. J Clin Psychiatry. 2004;6:79-86.

11. Savitz JB, Cupido CL, Ramesar RS. Trends in suicidology: personality as an endophenotype for molecular genetic investigations. PLoS Med. 2006;3:e107.

12. Baldwin D, Bullock T, Montgomery D, et al. 5-HT reuptake inhibitors, tricyclic antidepressants and suicidal behaviour. Int Clin Psychopharmacol. 1991;6 Suppl 3:49-55.

13. Isacsson G. Suicide prevention - a medical breakthrough? Acta Psychiatr Scand. 2000;102:113-117.

14. Teicher MH, Glod CA, Cole JO. Antidepressant drugs and the emergence of suicidal tendencies. Drug Saf. 1993;8:186-212.

15. Fergusson D, Doucette S, Glass KC, et al. Association between suicide attempts and selective serotonin reuptake inhibitors: systematic review of randomised controlled trials. BMJ. 2005;330:396-404.

16. Storosum JG, van Zwieten BJ, van den Brink W, et al. Suicide risk in placebo-controlled studies of major depression. Am J Psychiatry. 2001;158:1271-1275.

17. Khan A, Khan S, Kolts R, et al. Suicide rates in clinical trials of SSRIs, other antidepressants, and placebo: analysis of FDA reports. Am J Psychiatry. 2003;160:790-792.

18. Simon GE, Savarino J, Operskalski B, et al. Suicide risk during antidepressant treatment. Am J Psychiatry. 2006;163:41-47.

19. Castelpietra G, Morsanutto A, Pascolo-Fabrici E, et al. Antidepressant use and suicide prevention: a prescription database study in the region Friuli Venezia Giulia, Italy. Acta Psychiatr Scand. 2008. In press.

20. Kalmar S, Szanto K, Rihmer Z, et al. Antidepressant prescription and suicide rates: effect of age and gender. Suicide Life Threat Behav. 2008;38:363-374.

21. Stahl SM, Grady MM, Moret C, et al. SNRIs: their pharmacology, clinical efficacy, and tolerability in comparison with other classes of antidepressants. CNS Spectr. 2005;10:732-747.

22. Beck AT, Kovacs M, Weissman A. Assessment of suicidal intention: the Scale for Suicide Ideation. J Consult Clin Psychol. 1979;47: 343-352.

23. Möller HJ. Antidepressants - do they decrease or increase suicidality? Pharmacopsychiatry. 1992;25:249-253.

24. Acharya N, Rosen AS, Polzer JP, et al. Duloxetine: meta-analyses of suicidal behaviors and ideation in clinical trials for major depressive disorder. J Clin Psychopharmacol. 2006;26:587-594.
Neuropsychiatric Disease and Treatment

\section{Publish your work in this journal}

Neuropsychiatric Disease and Treatment is an international, peerreviewed journal of clinical therapeutics and pharmacology focusing on concise rapid reporting of clinical or pre-clinical studies on a range of neuropsychiatric and neurological disorders. This journal is indexed on PubMed Central, the 'PsycINFO' database and CAS, and is the official

\section{Dovepress}

journal of The International Neuropsychiatric Association (INA). The manuscript management system is completely online and includes a very quick and fair peer-review system, which is all easy to use. Visit $\mathrm{http}: / / \mathrm{www}$.dovepress.com/testimonials.php to read real quotes from published authors. 